\title{
Chronic Inflammation and Coronary Atherosclerosis in Patients with End-Stage Renal Disease
}

\author{
Maen B. Nusair Naveen Rajpurohit Martin A. Alpert \\ Division of Cardiovascular Medicine, University of Missouri-Columbia, Columbia, Mo., USA
}

\section{Key Words}

Coronary atherosclerosis $\cdot$ End-stage renal disease $\cdot$ Chronic inflammation

\begin{abstract}
The key role of chronic inflammation in the pathogenesis of atherosclerosis has become increasingly apparent in recent years based on the results of experimental, epidemiologic and clinical studies. Coronary artery disease and its complications occur with disproportionately high frequency in patients with end-stage renal disease (ESRD) and contribute substantially to cardiovascular morbidity and mortality in this population. Traditional cardiovascular risk factors occur commonly in patients with ESRD. In addition, a variety of patient-related and dialysis-related factors unique to ESRD predispose to chronic inflammation and by doing so are thought to contribute to coronary atherosclerosis and its complications. These risk factors may serve as therapeutic targets and as such may offer the potential for altering the natural history of coronary atherosclerosis in ESRD.

Copyright $\odot 2012$ S. Karger AG, Basel
\end{abstract}

\section{Introduction}

During the past two decades it has become increasingly clear that inflammation plays a key role in all stages of atherosclerosis, from its inception, through its progression to its final complication of thrombosis. The atheroma is a highly active cellular lesion. Many of the cells present in atheromata facilitate or result from inflammation. Patients with advanced chronic kidney disease and particularly those with ESRD have a higher prevalence of coronary artery disease than the general population. The role of chronic inflammation as a putative cause of high morbidity and mortality in these patients has gained considerable attention in recent years. In this review we discuss the pathogenesis of atherosclerosis in general and in patients with ESRD with special emphasis of the role of chronic inflammation. 


\section{CardioRenal Medicine}

\section{Pathogenesis of Atherosclerosis}

Under normal conditions, endothelial cells in the arterial wall resist adhesion and aggregation of leukocytes. When endothelial injury occurs from such factors as hypertension or cigarette smoking, low density lipoprotein molecules infiltrate the arterial wall and undergo oxidation by intimal enzymes [1]. This process results in endothelial cell activation and upregulation of several types of leukocyte adhesion molecules [2]. These molecules enable leukocytes along the vascular surface to adhere to the site of activation. Vascular cell adhesion molecule-1 (VCAM-1) has been shown to play a dominant role in this process [3]. Monocytes and lymphocytes preferentially bind to VCAM-1. Once attached, chemokines produced in the underlying intima stimulate these cells to migrate through the inter-endothelial junctions and into the sub-endothelial space [4]. The chemoattractant cytokine monocyte chemoattractant protein-1 is now recognized as a major facilitator of monocyte migration. It interacts with the monocyte chemokine receptor CCR2, recruiting monocytes to the arterial endothelium and facilitating their entry between endothelial cells by diapedesis [5].

Once in the subintimal space, monocytes differentiate into macrophages through the action of macrophage colony-stimulating factor. Macrophages express scavenger receptors that allow them to engulf modified lipoprotein particles. The cytoplasm becomes engorged with lipid particles giving the macrophages the typical microscopic frothy appearance of the foam cells found in atherosclerotic lesions [6].

Macrophages also express toll-like receptors. In contrast to scavenger receptors, toll-like receptors can initiate a signal cascade that leads to cell activation [7]. The activated macrophage produces inflammatory cytokines, proteases, and cytotoxic oxygen and nitrogen radical species. Oxidized low density lipoprotein and heat shock proteins are among the recognized activators of these receptors [8]. Cells in human atherosclerotic lesions display a spectrum of toll-like receptors, and plaque inflammation may depend in part on this pathway [9]. Atheromata contain relatively small populations of T lymphocytes. Although numerically a minority of leukocytes in plaque, these cells of the adaptive immune response exert critical regulatory effects on the more abundant monocytes. The T cells in plaque also display heterogeneity of function. Some subsets appear to be pro-inflammatory (T-helper 1 cells), while others tend to suppress inflammation (T-helper 2 cells) [10-12]. The atherosclerotic lesion contains cytokines that promote a T-helper 1 response. T-helper 1 cells produce interferon- $\gamma$ which activates macrophages and augments synthesis of the inflammatory cytokine tumor necrosis factor and interleukin (IL) 1 . These cytokines trigger the production of many inflammatory and cytotoxic molecules in macrophages and vascular cells which further perpetuate inflammation [9]. It bears emphasis that despite the fact that T-helper 2 cells produce anti-atherosclerotic cytokines, these cells also promote elastolysis which instigates aneurysm formation [13]. Consequently, whether there is a predominant T-helper 1 or T-helper 2 response within plaque, vascular disease may still develop; however its phenotype may differ.

\section{Inflammation and Atherothrombosis}

Functional attributes rather than size alone determine the propensity of atherosclerotic plaques to provoke acute coronary syndromes [14]. Inflammation appears to be a major determinant of the fragility of the plaque's fibrous cap, as well as its thrombogenic potential. $\mathrm{T}$ cells induce the production of different matrix metalloproteinases such as proteinase collagenase and stromelysin as well as the expression of the pro-coagulant tissue factor [14]. Mac- 


\section{CardioRenal Medicine}

\begin{tabular}{l|l}
\hline Cardiorenal Med 2012;2:117-124 \\
\hline DOI: 10.1159/000337082 & $\begin{array}{l}\text { @ 2012 S. Karger AG, Basel } \\
\text { www.karger.com/crm }\end{array}$ \\
\hline Published online: March 20, 2012 &
\end{tabular}

Nusair et al.: Inflammation, Atherosclerosis and End-Stage Renal Disease

rophage-derived matrix metalloproteinase digests the plaque's extracellular matrix, thus impairing fibrous cap stability and predisposing to plaque rupture. This in turn exposes circulating blood components to the tissue factor-rich lipid core, inciting thrombosis [15].

\section{Role of Inflammatory Biomarkers in Predicting Coronary Events}

Of the many inflammatory markers implicated in atherosclerosis $\mathrm{C}$-reactive protein (CRP) has been studied most extensively. It remains unresolved as to whether serum CRP is a nonspecific marker that is increased as part of the acute phase response to inflammation or a direct participant in the progression of atherosclerosis and its clinical consequences. There is growing evidence however, that the relation is not causal [16-19].

Multiple large-scale, prospective cohort studies indicate that high-sensitivity CRP (hsCRP) predicts incident myocardial infarction, ischemic stroke, and cardiovascular death, even after adjustment for traditional risk factors in subjects at low and at high risk for these events [20-23]. In the Women Health Study, Ridker et al. [24] studied 28,263 apparently healthy postmenopausal women over a mean follow-up period of 3 years. The risk of cardiovascular events associated with baseline levels of markers of inflammation was assessed. The markers included hs-CRP, serum amyloid A, IL- 6 and soluble intercellular adhesion molecule-1. Of all the markers measured, hs-CRP was the strongest univariate predictor of the risk of cardiovascular events. The relative risk of events for women in the highest as compared with the lowest quartile for this marker was 4.4 (95\% confidence interval 2.2-8.9).

In the JUPITER (Justification for the Use of Statins in Prevention: an Intervention Trial Evaluating Rosuvastatin) Ridker et al. [25] tested the hypothesis that people with elevated hs-CRP levels, but without hyperlipidemia would benefit from statin treatment. The trial enrolled 17,802 individuals without manifest cardiovascular disease, with low density lipoprotein cholesterol levels $<130 \mathrm{mg} / \mathrm{dl}$, but with hs-CRP levels $>2 \mathrm{mg} / \mathrm{l}$. All study participants were randomly allocated to oral rosuvastatin $20 \mathrm{mg}$ daily or to a placebo and were then followed for incidence of vascular events. The trial was terminated early due to a $44 \%$ reduction in the primary end point of all vascular events $(\mathrm{p}=0.00001)$. There was also a $54 \%$ reduction in myocardial infarction $(\mathrm{p}=0.0002)$, a $48 \%$ reduction in stroke $(\mathrm{p}=0.002)$, a $46 \%$ reduction in the need for arterial revascularization ( $\mathrm{p}=0.0001)$, and a $20 \%$ reduction in all-cause mortality. All pre-specified subgroups within the trial significantly benefitted from rosuvastatin therapy, including those groups traditionally considered to be at low risk. The authors concluded that in apparently healthy individuals without hyperlipidemia but with an elevated hs-CRP level rosuvastatin significantly reduced the incidence of major cardiovascular events [25].

\section{Coronary Artery Disease in Patients with End-Stage Renal Disease}

The presence of cardiovascular disease is an important predictor of mortality in patients with end-stage renal disease (ESRD). It accounts for $45-50 \%$ of deaths in patients receiving dialysis [26-29]. Twenty percent of deaths are attributable to coronary artery disease and its complications.

At the time of enrollment in the Hemodialysis (HEMO) study, nearly $40 \%$ of the 1,846 hemodialysis patients entered were noted to have ischemic heart disease [26]. During the mean follow-up period of 2.8 years, angina pectoris and acute myocardial infarction were responsible for $43 \%$ of all cardiac hospitalizations, with ischemic heart disease accounting for $62 \%$ [26]. 


\section{CardioRenal Medicine}

\begin{tabular}{l|l}
\hline \multicolumn{2}{l}{ Cardiorenal Med 2012;2:117-124 } \\
\hline DOI: 10.1159/000337082 & $\begin{array}{l}\text { @ 2012 S. Karger AG, Basel } \\
\text { www.karger.com/crm }\end{array}$ \\
Published online: March 20, 2012 &
\end{tabular}

Nusair et al.: Inflammation, Atherosclerosis and End-Stage Renal Disease
Fig. 1. Mechanisms by which traditional cardiovascular risk factors combine with risk factors for chronic inflammation to lead to accelerated atherosclerosis. Traditional cardiovascular risk factors combine with uremia and dialysis-related risk factors to cause endothelial dysfunction and pro-inflammatory cytokine release. This stimulates production of acute phase reactants (CRP, serum amyloid A, fibrinogen) ultimately leading to accelerated atherosclerosis.

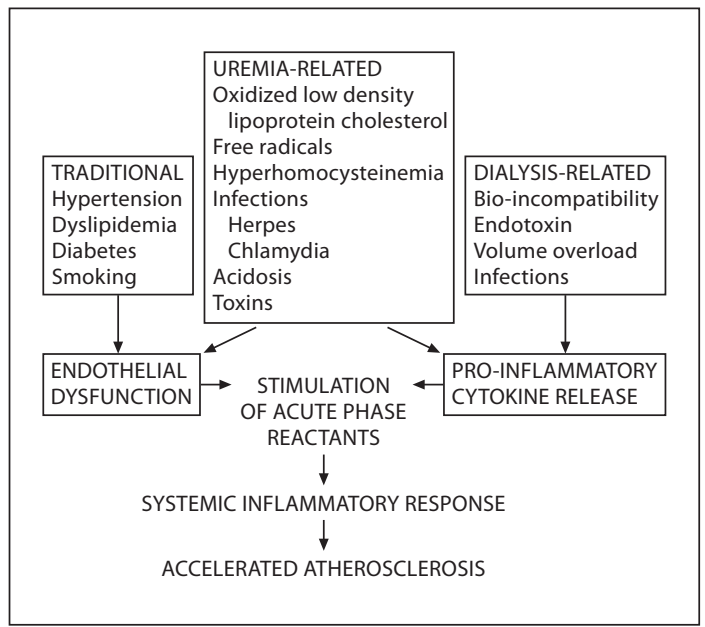

In addition, ESRD patients have a high incidence of occult coronary artery disease. Occult and/or silent myocardial ischemia is also observed in a significant number of dialysis patients. In one study, $>50 \%$ stenosis of at least one major coronary artery was found on coronary angiography in 16 of 30 asymptomatic patients (53\%) beginning renal replacement therapy [27]. In a second coronary angiographic study of 67 asymptomatic patients, 28 (42\%) had $\geq 50 \%$ stenosis in at least one major coronary artery, while $19(29 \%)$ had $\geq 50 \%$ stenosis within the proximal third of at least one epicardial coronary artery [28].

Data from the USRDS demonstrate that in ESRD all-cause cardiovascular mortality increases sharply with systolic blood pressures $<110 \mathrm{~mm} \mathrm{Hg}$, but is relatively flat afterward [29]. Similarly, mortality is higher in patients with lower cholesterol levels irrespective of the use of lipid-lowering medications [30]. It is now generally accepted that this seeming paradox is most likely due to confounding factors, whereby patients with ESRD who are predisposed to adverse outcomes are already malnourished and have a higher incidence of dialysis and hypotension [31].

\section{ESRD and Inflammation}

The role of chronic inflammation as a putative cause of high mortality in ESRD has attracted considerable interest during the last decade. It has been hypothesized that in addition to its direct pro-atherogenic effects, chronic inflammation may serve as a catalyst and in the toxic uremic milieu may modulate the effects of concurrent vascular and nutritional risk factors [32].

ESRD has become a prototype for chronic inflammation. There is consistent evidence that CRP and pro-inflammatory cytokines such as IL-1, IL- 6 and TNF- $\alpha$ are risk factors for atherosclerotic complications and predict death and adverse cardiovascular outcomes in these patients [33-36]. Schwarz et al. [37] have shown that coronary atherosclerotic plaques in ESRD patients are characterized by increased medial thickness, infiltration by and activation of macrophages and marked calcification. Available evidence suggests that heavily calcified and inflamed plaques contribute to excessive cardiovascular risk in ESRD patients [38].

Figure 1 summarizes the mechanisms by which risk factors for chronic inflammation lead to accelerated atherosclerosis. Uremic toxin accumulation (which is only partially cor- 


\section{CardioRenal Medicine}

\begin{tabular}{l|l}
\hline \multicolumn{2}{l}{ Cardiorenal Med 2012;2:117-124 } \\
\hline DOI: 10.1159/000337082 & $\begin{array}{l}\text { @ 2012 S. Karger AG, Basel } \\
\text { www.karger.com/crm }\end{array}$ \\
Published online: March 20, 2012 &
\end{tabular}

Nusair et al.: Inflammation, Atherosclerosis and End-Stage Renal Disease

rected by dialysis) as well as dialysis-related factors, such as bio-incompatibility between blood and dialyzer, the presence of endotoxin in dialysis fluid, access-related infections, peritoneal dialysis solutions with a high glucose concentration, low $\mathrm{pH}$ and the presence of glucose degradation products have been implicated in feeding the inflammation cycle in ESRD patients [39]. Recent studies suggest that the reduction of renal function per se may also be associated with an inflammatory response. As renal function deteriorates during the progression of renal disease, an increase in the concentration of plasma pro-inflammatory cytokines and other inflammatory biomarkers is observed in both mild and advanced renal failure [ 40 , 41]. In addition, uremia and renal replacement therapies result in markedly enhanced oxidative stress, the production of complement fragments and cytokines, increased adhesion molecules in endothelial cells and other pro-inflammatory factors such as TNF- $\alpha$ and CRP [18].

Recently, McIntyre et al. [42] studied circulating endotoxin levels in 249 stage 3-5 chronic kidney disease (CKD) patients and a comparator cohort of hypertensive patients without renal impairment. They found that circulating endotoxemia was most notable in those with the highest cardiovascular disease burden (increasing with CKD stage). A sharp increase was observed after initiation of hemodialysis. In hemodialysis patients, pre-dialysis endotoxin levels appeared to be related to dialysis-induced hemodynamic stress (ultrafiltration volume, relative hypotension), myocardial stunning, serum cardiac troponin $\mathrm{T}$ and hs-CRP. The authors postulated that hemodialysis-induced systemic circulatory stress and recurrent regional ischemia may lead to increased endotoxin translocation from the gut. The resultant endotoxemia is thought to contribute to systemic inflammation, generation of markers of malnutrition, cardiac injury and reduced survival [42].

Uremic atherosclerosis is associated with the generation of advanced glycation end products [43]. Advanced glycation end products activate monocytes/macrophages and endothelial cells and result in release of cytokines and growth factors [44]. Advanced glycation end products may also contribute to oxidative stress, inflammation, an increase in extracellular matrix and abnormal cell proliferation in ESRD patients [43, 44].

Levels of CRP increase as the renal function deteriorates and are particularly high in patients with ESRD. As many as one third to one half of patients with ESRD have CRP levels in the very high-risk category, and CRP continues to be an excellent predictor of adverse outcome in this population [45]. Parekh et al. [46] prospectively studied a cohort of more than 1,000 ESRD patients followed for a median of 2.5 years and reported that the highest tertile of CRP was associated with a two-fold increased adjusted risk of sudden cardiac death compared to patients in the lowest tertile. The major stimulus for increased CRP release by the liver was IL- 6 which is produced by the intra-abdominal adipocytes; hence the association between obesity and increased inflammation in CKD [47]. IL-6 may also directly act as a promoter of atherosclerosis and wasting by actively participating in the processes of vascular calcification, muscle catabolism, oxidative stress, anorexia, cell aging, hormonal derangements, and endothelial dysfunction [32].

Among 3,267 patients with moderate CKD, CRP levels $\geq 2 \mathrm{mg} / \mathrm{l}$ and a low density lipoprotein level $\leq 130 \mathrm{mg} / \mathrm{dl}$ in the JUPITER trial treatment with rosuvastatin led to a $37 \%$ decrease of CRP levels which was associated with significant reductions in cardiovascular events and all-cause mortality [25]. In contrast, the reported effects of statins on inflammatory biomarkers in ESRD are not as consistent. In a study of 1,255 diabetic patients receiving hemodialysis reported by Krane et al. [48] atorvastatin had no significant effect on the risk of the composite end point of myocardial infarction, stroke, or death relative to placebo in any quartile of baseline CRP. In the AURORA study, 2,776 dialysis patients were treated with rosuvastatin versus placebo and were followed for 3.6 years [49]. No significant differences in the incidence of cardiovascular events between the two groups were noted during the follow-up period [49]. 


\section{CardioRenal Medicine}

\begin{tabular}{l|l}
\hline \multicolumn{2}{l}{ Cardiorenal Med 2012;2:117-124 } \\
\hline DOI: 10.1159/000337082 & $\begin{array}{l}\text { @ 2012 S. Karger AG, Basel } \\
\text { www.karger.com/crm }\end{array}$ \\
Published online: March 20, 2012 &
\end{tabular}

Nusair et al.: Inflammation, Atherosclerosis and End-Stage Renal Disease

Stenvinkel and others [32-35] have emphasized the link between malnutrition and inflammation in dialysis patients. The malnutrition inflammation complex syndrome predisposes to a variety of clinical and metabolic derangements including atherosclerotic cardiovascular disease.

\section{Emerging Therapies Targeting Inflammation: Role of Anti-Cytokines}

Don et al. [50] reported the results of a pilot study to determine whether treatment with the TNF- $\alpha$ receptor antagonist etanercept was safe and whether its use would result in increased levels of albumin and pre-albumin in inflamed hypoalbuminemic (albumin $<3.8 \mathrm{~g}$ / $\mathrm{dl}, \mathrm{CRP}>8.0 \mathrm{mg} / \mathrm{l})$ prevalent hemodialysis patients. Etanercept increased pre-albumin by $20 \%$; however, no significant change in CRP was noted [50].

Hung et al. [51] recently published the results of a randomized placebo-controlled trial to evaluate the efficacy of the administration of recombinant human IL-1 receptor antagonist (IL-1RA) on biomarkers of inflammation and nutrition in hemodialysis patients with serum hs-CRP levels $>5 \mathrm{mg} / \mathrm{l}$. After four weeks, those who received IL-1RA treatment showed a 53\% reduction in CRP levels, a 40\% reduction in IL-6 levels and $23 \%$ increase in pre-albumin levels [51]. Larger studies are now needed to test the effects of selective antiTNF- $\alpha$, anti-IL-1, and anti-IL- 6 therapies, not only on inflammatory and nutritional surrogate markers, but also on morbidity and mortality [52]. The major difficulty will be to select patients with persistent non-infectious uremic inflammation [52]. Until adequately-powered randomized, controlled trials have been performed with anti-inflammatory treatment strategies, no specific pharmacological treatment recommendations for uremic inflammation can be advocated [52].

\section{Conclusion}

ESRD is characterized by an exceptionally high mortality rate, largely related to cardiovascular disease, including accelerated atherosclerosis and its complications. The accelerated atherosclerotic process in these patients is attributable, at least in part, to chronic inflammation. As the mechanisms responsible for this inflammatory response have become increasingly clear, the potential exists for developing therapies targeting inflammation which may reduce cardiovascular disease and improve prognosis in patients with ESRD.

\section{References}

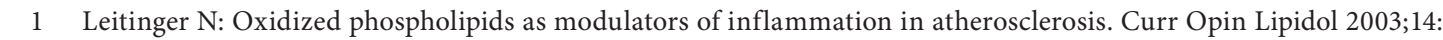
421-430.

-2 Dai G, Kaazempur-Mofrad MR, Natarajan S, Zhang Y, Vaughn S, Blackman BR, Kamm RD, Garcia-Cardena G, Gimbrone MA Jr: Distinct endothelial phenotypes evoked by arterial waveforms derived from atherosclerosis-susceptible and resistant regions of human vasculature. Proc Natl Acad Sci USA 2004;101:14871-14876.

-3 Cybulsky MI, Iiyama K, Li H, Zhu S, Chen M, Iiyama M, Davis V, Gutierrez-Ramos JC, Connelly PW, Milstone DS: A major role for VCAM-1, but not ICAM-1, in early atherosclerosis. J Clin Invest 2001;107:1255-1262.

4 Cybulsky MI, Gimbrone MA Jr: Endothelial expression of a mononuclear leukocyte adhesion molecule during atherogenesis. Science 1991;251:788-791.

5 Boring L, Gosling J, Cleary M, Charo IF: Decreased lesion formation in CCR2-/- mice reveals a role for chemokines in the initiation of atherosclerosis. Nature 1998;394:894-897.

6 Libby P, Okamoto Y, Rocha VZ, Folco E: Inflammation in atherosclerosis: transition from theory to practice. Circ J 2010;74:213-220. 


\section{CardioRenal Medicine}

\begin{tabular}{l|l}
\hline \multicolumn{2}{l}{ Cardiorenal Med 2012;2:117-124 } \\
\hline DOI: 10.1159/000337082 & $\begin{array}{l}\text { @ 2012 S. Karger AG, Basel } \\
\text { www.karger.com/crm }\end{array}$ \\
Published online: March 20, 2012 &
\end{tabular}

Nusair et al.: Inflammation, Atherosclerosis and End-Stage Renal Disease

$>7$

$>8$

$>9$

10

$>11$

$>12$

$>13$

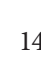

14

$>15$

$\checkmark 16$

$-17$

${ }_{18}$

${ }_{19}$

20

$-21$

$-22$

23

23

$-24$

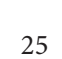

$>25$

$-26$

$-27$

$\mathrm{O}$ artery stenosis in patients with chronic kidney disease at the initiation of renal replacement therapy: an angiographic examination. J Am Soc Nephrol 2005;16:1141-1148.

28 Charytan D, Kuntz RE, Mauri L, DeFilippi C: Distribution of coronary artery disease and relation to mortality in asymptomatic hemodialysis patients. Am J Kidney Dis 2007;49:409-416.

29 Goldfarb-Rumyantzev AS, Baird BC, Leypoldt JK, Cheung AK: The association between BP and mortality in patients on chronic peritoneal dialysis. Nephrol Dial Transplant 2005;20:1693-1701.

-30 Habib AN, Baird BC, Leypoldt JK, Cheung AK, Goldfarb-Rumyantzev AS: The association of lipid levels with mortality in patients on chronic peritoneal dialysis. Nephrol Dial Transplant 2006;21:2881-2892.

-31 Kalantar-Zadeh K, Abbott KC, Kronenberg F, Anker SD, Horwich TB, Fonarow GC: Epidemiology of dialysis patients and heart failure patients. Semin Nephrol 2006;26:118-133.

32 Carrero JJ, Stenvinkel P: Persistent inflammation as a catalyst for other risk factors in chronic kidney disease: a hypothesis proposal. Clin J Am Soc Nephrol 2009;4(suppl 1):S49-S55.

33 Stenvinkel P, Barany P, Heimburger O, Pecoits-Filho R, Lindholm B: Mortality, malnutrition, and atherosclerosis in ESRD: what is the role of interleukin-6? Kidney Int Suppl 2002:103-108.

$\checkmark 34$ Zoccali C, Benedetto FA, Mallamaci F, Tripepi G, Fermo I, Foca A, Paroni R, Malatino LS: Inflammation is associated with carotid atherosclerosis in dialysis patients. Creed Investigators. Cardiovascular Risk Extended Evaluation in Dialysis Patients. J Hypertens 2000;18:1207-1213.

-35 Stenvinkel P, Heimburger O, Jogestrand T: Elevated interleukin-6 predicts progressive carotid artery atherosclerosis in dialysis patients: association with Chlamydia pneumoniae seropositivity. Am J Kidney Dis 2002;39:274-282.

36 Yeun JY, Levine RA, Mantadilok V, Kaysen GA: C-Reactive protein predicts all-cause and cardiovascular mortality in hemodialysis patients. Am J Kidney Dis 2000;35:469-476.

-37 Schwarz U, Buzello M, Ritz E, Stein G, Raabe G, Wiest G, Mall G, Amann K: Morphology of coronary atherosclerotic lesions in patients with end-stage renal failure. Nephrol Dial Transplant 2000;15:218-223.

38 Stenvinkel P, Pecoits-Filho R, Lindholm B: Coronary artery disease in end-stage renal disease: no longer a simple plumbing problem. J Am Soc Nephrol 2003;14:1927-1939. 


\section{CardioRenal Medicine}

\begin{tabular}{l|l}
\hline \multicolumn{2}{l}{ Cardiorenal Med 2012;2:117-124 } \\
\hline DOI: 10.1159/000337082 & $\begin{array}{l}\text { @ 2012 S. Karger AG, Basel } \\
\text { www.karger.com/crm }\end{array}$ \\
\hline Published online: March 20, 2012 &
\end{tabular}

Nusair et al.: Inflammation, Atherosclerosis and End-Stage Renal Disease

-39 Kato S, Chmielewski M, Honda H, Pecoits-Filho R, Matsuo S, Yuzawa Y, Tranaeus A, Stenvinkel P, Lindholm B: Aspects of immune dysfunction in end-stage renal disease. Clin J Am Soc Nephrol 2008;3:1526-1533.

-40 Shlipak MG, Fried LF, Crump C, Bleyer AJ, Manolio TA, Tracy RP, Furberg CD, Psaty BM: Elevations of inflammatory and procoagulant biomarkers in elderly persons with renal insufficiency. Circulation 2003;107:87-92.

-41 Pecoits-Filho R, Heimburger O, Barany P, Suliman M, Fehrman-Ekholm I, Lindholm B, Stenvinkel P: Associations between circulating inflammatory markers and residual renal function in CRF patients. Am J Kidney Dis 2003;41: 1212-1218.

-42 McIntyre CW, Harrison LE, Eldehni MT, Jefferies HJ, Szeto CC, John SG, Sigrist MK, Burton JO, Hothi D, Korsheed S, Owen PJ, Lai KB, Li PK: Circulating endotoxemia: a novel factor in systemic inflammation and cardiovascular disease in chronic kidney disease. Clin J Am Soc Nephrol 2011;6:133-141.

43 Miyata T, van Ypersele de Strihou C, Kurokawa K, Baynes JW: Alterations in nonenzymatic biochemistry in uremia: origin and significance of 'carbonyl stress' in long-term uremic complications. Kidney Int 1999;55:389-399.

-44 Raj DS, Choudhury D, Welbourne TC, Levi M: Advanced glycation end products: a nephrologist's perspective. Am J Kidney Dis 2000;35:365-380.

45 Stenvinkel P, Alvestrand A: Inflammation in end-stage renal disease: sources, consequences, and therapy. Semin Dial 2002;15:329-337.

46 Parekh RS, Plantinga LC, Kao WH, Meoni LA, Jaar BG, Fink NE, Powe NR, Coresh J, Klag MJ: The association of sudden cardiac death with inflammation and other traditional risk factors. Kidney Int 2008;74:1335-1342.

-47 Ramkumar N, Cheung AK, Pappas LM, Roberts WL, Beddhu S: Association of obesity with inflammation in chronic kidney disease: a cross-sectional study. J Renal Nutr 2004;14:201-207.

48 Krane V, Winkler K, Drechsler C, Lilienthal J, Marz W, Wanner C: Effect of atorvastatin on inflammation and outcome in patients with type 2 diabetes mellitus on hemodialysis. Kidney Int 2008;74:1461-1467.

-49 Fellstrom BC, Jardine AG, Schmieder RE, Holdaas H, Bannister K, Beutler J, Chae DW, Chevaile A, Cobbe SM, Gronhagen-Riska C, De Lima JJ, Lins R, Mayer G, McMahon AW, Parving HH, Remuzzi G, Samuelsson O, Sonkodi S, Sci D, Suleymanlar G, Tsakiris D, Tesar V, Todorov V, Wiecek A, Wuthrich RP, Gottlow M, Johnsson E, Zannad F: Rosuvastatin and cardiovascular events in patients undergoing hemodialysis. N Engl J Med 2009;360:1395-1407.

50 Don BR, Kim K, Li J, Dwyer T, Alexander F, Kaysen GA: The effect of etanercept on suppression of the systemic inflammatory response in chronic hemodialysis patients. Clin Nephrol 2010;73:431-438.

51 Hung AM, Ellis CD, Shintani A, Booker C, Ikizler TA: IL-1beta receptor antagonist reduces inflammation in hemodialysis patients. J Am Soc Nephrol 2011;22:437-442.

52 Miyamoto T, Carrero JJ, Stenyinkel P: Inflammation as a risk factor target for therapy in chronic kidney disease. Curr Opin Nephrol Hypertension 2011;20:662-668. 